\title{
Development and hormonal functions of the human placenta
}

\author{
Jean Guibourdenche $1,2,3,4$, Thierry Fournier ${ }^{1,2,3}$, André Malassiné1,2, \\ Daniele Evain-Brion ${ }^{1,2,3}$
}

\author{
${ }^{1}$ INSERM, U767, 4 Avenue de l'Observatoire,75006, Paris, France \\ ${ }^{2}$ Université Paris Descartes, Paris, France \\ ${ }^{3}$ PremUP, Fondation, Paris, France \\ ${ }^{4}$ Prenatal diagnosis, CHU Cochin-Saint Vincent de Paul, AP-HP
}

\begin{abstract}
The human placenta is characterized by the intensity of the trophoblast invasion into the uterus wall and the specificity of its hormonal functions. Placental hormones are required for the establishment and maintenance of pregnancy, adaptation of the maternal organism to pregnancy and fetal growth. In the early placenta at the maternofetal interface, the human trophoblast differentiates along two pathways: 1/ the villous trophoblast pathway including the cytotrophoblastic cells which differentiate by fusion to form the syncytiotrophoblast that covers the entire surface of the villi; $2 /$ the extravillous trophoblast pathway. The cytotrophoblastic cells of the anchoring villi in contact with the uterus wall proliferate and then migrate into the decidua and the myometrium but also participate to the remodeling of the spiral arteries. During the first trimester of pregnancy the spiral arteries are plugged by trophoblastic cells, allowing the development of the fetoplacental unit in low oxygen environment. At this stage of pregnancy the extravillous trophoblast secretes a large amount of hormones such as particular hyperglycosylated forms of hCG directly involved in the quality of the placentation. At 10-12 weeks of pregnancy, the trophoblastic plugs are progressively dislocated and the syncytiotrophoblast starts to bath in maternal blood. It secretes the major part of its polypeptide hormones in maternal circulation taking over the maternal metabolism in order to increase the energetic flux to the fetus. As example the placental GH (growth hormone) secreted continuously by the syncytiotrophoblast is directly involved in the insulino-resistance of pregnancy. Capturing the cholesterol from the maternal lipoproteins, the syncytiotrophoblast synthesizes also large amount of progesterone essential for the uterine quiescence. Deprived of cytochrome P450 17 $\alpha$-hydroxylase-17:20 lyase, it uses the maternal and fetal adrenal androgens to synthesize estrogens. The differentiation and hormonal functions of the human trophoblast are regulated by the environmental $\mathrm{O} 2$ and reflect mammalian evolution.
\end{abstract}

Key words: trophoblast, differentiation, cell fusion, cell invasion, hCG, placental growth hormone, pregnancy hormones

\section{Human placental development}

The human placenta is a villous placenta; the structural and functional unit of the human placenta is the chorionic villous which becomes apparent in its definitive structure as early as day 21 of pregnancy [1] (Fig. 1). After nidation, the trophoblast differentiates in two ways: the villous and the extra-villous trophoblast. In the villous phenotype, the cytotrophoblastic cells (CT) of the floating villi (in the intervillous space) remain attached to the villous basement membrane, forming

Correspondence: D. Evain-Brion, INSERM, U767, 4 Avenue de l'Observatoire, 75006, Paris, France;

e-mail: daniele.evain-brion@parisdescartes.fr a monolayer of epithelial cells. These cells proliferate and differentiate, by fusion, to form a syncytiotrophoblast that covers the entire surface of the villus (Fig. 1). This multinucleated syncytiotrophoblast is regenerated along pregnancy by a continuous turnover process including proliferation of mononuclear $\mathrm{CT}$ followed by the induction of early stages of apoptosis and fusion of these CT into ST. Apoptotic progression in the ST leads to the accumulation of condensed nuclei into syncytial knots and the shedding of these aggregates into the intervillous spaces. This membrane fusion process is complex and involves different factors [see for review 2]. Among them endogenous retroviral envelope proteins (syncytins), are specifically expressed in the trophoblast; syncytin 1, the envelop 


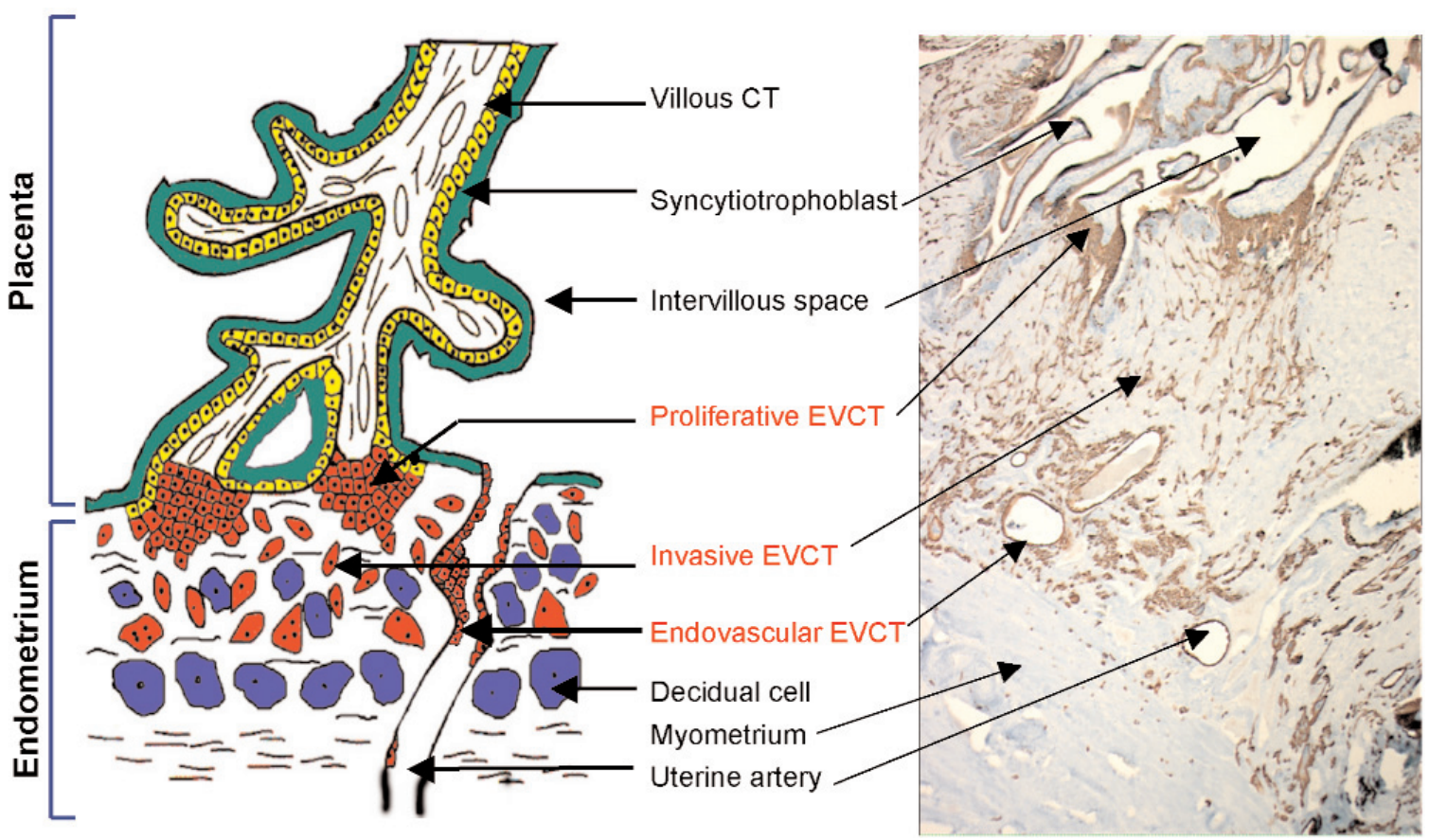

Fig. 1 Left panel. Scheme of human chorionic villi. Right panel Immunoshistochemistry analysis of trophoblast differentiation in the implantation site of early human placenta. Paraffin-embedded sections of an implantation site (placenta and myometrium) at 16 weeks of pregnancy was obtained from the Department of Pathology CHR La Citadelle, Liege. Hysterectomy was performed because of cervical carcinoma stage IIa diagnosed at 16 weeks of gestation. Samples were fixed in $4 \%$ formalin for 4 to $12 \mathrm{~h}$ at room temperature. Use of these biological samples, were approved by local ethical committee. Sections were stained for cytokeratine 07 to identify trophoblastic cells. IS= intervillous space, PEVCT= proliferative extravillous cytotrophoblastic cells, IEVCT= invasive extravillous cytotrophoblastic cells, ST= syncytiotrophoblast.

glycoprotein of HERVW retrovirus is directly involved in trophoblast fusion and differentiation [3]. In the extravillous phenotype, the cytotrophoblastic cells of the anchoring villi in contact with the uterine wall proliferate, detach from the basement membrane and aggregate into multilayered columns of nonpolarised cells that rapidly invade the uterus wall. This trophoblastic invasion is confined to the endometrium, the first third of the myometrium, and the associated spiral arterioles. This invasion process is associated with complete remodeling of the spiral artery wall, leading to the disappearance of the muscle layer and replacement of endothelial cells by trophoblasts [4]. This trophoblastic endovascular and perivascular invasion is of major importance for feto-placental physiology: intra-arterial plugs of endovascular trophoblasts prevent, until the twelfth week of gestation, access of maternal blood to the intervillous space and therefore protect the conceptus from excessively high oxygen levels during this very critical stage of development (Fig. 2) $[5,6]$.

As illustrated in Fig. 3 primary culture of trophoblast cells are usefull models to study human trophoblast differentiation. Extravillous cytotrophoblastic cells can be isolated from first trimester anchoring chorionic villi. When plated on extracellular matrix substrates they recapitulate the differentiation process that lead to invasion in vivo [7]. Primary culture cells have also thrown light on human villous trophoblast differentiation. Isolated villous cytotrophoblast from early and term placenta adhere to plastic dish, aggregate and fuse together to form a non proliferative multinucleated syncytiotrophoblast which expresses specific hormonal production [8]. Different permanent trophoblast cell lines are also available. They offer an easy accessible model to study some aspects of gene expression and regulation in cells derived from trophoblast. However these highly proliferative cell lines do not reflect necessarily the complex phenotype of villous or extravillous trophoblast [9]. Therefore cautions must be taken before extrapolating results obtained in these cell lines to normal trophoblast.

\section{Human placental hormonal functions}

The human placenta is characterized by the intensity and specificity of its hormonal functions. Indeed the human trophoblast secretes many polypeptide hormones and a large amount of steroid hormones. The polypeptide hormones are primarily: hCG (human chorionic gonadotropin), hPL (human placental lactogen) or hCS ( human somatomammotropic hormone) and placental GH (growth hormone). The glycoprotein hormone hCG, is the key hormone of human pregnan- 

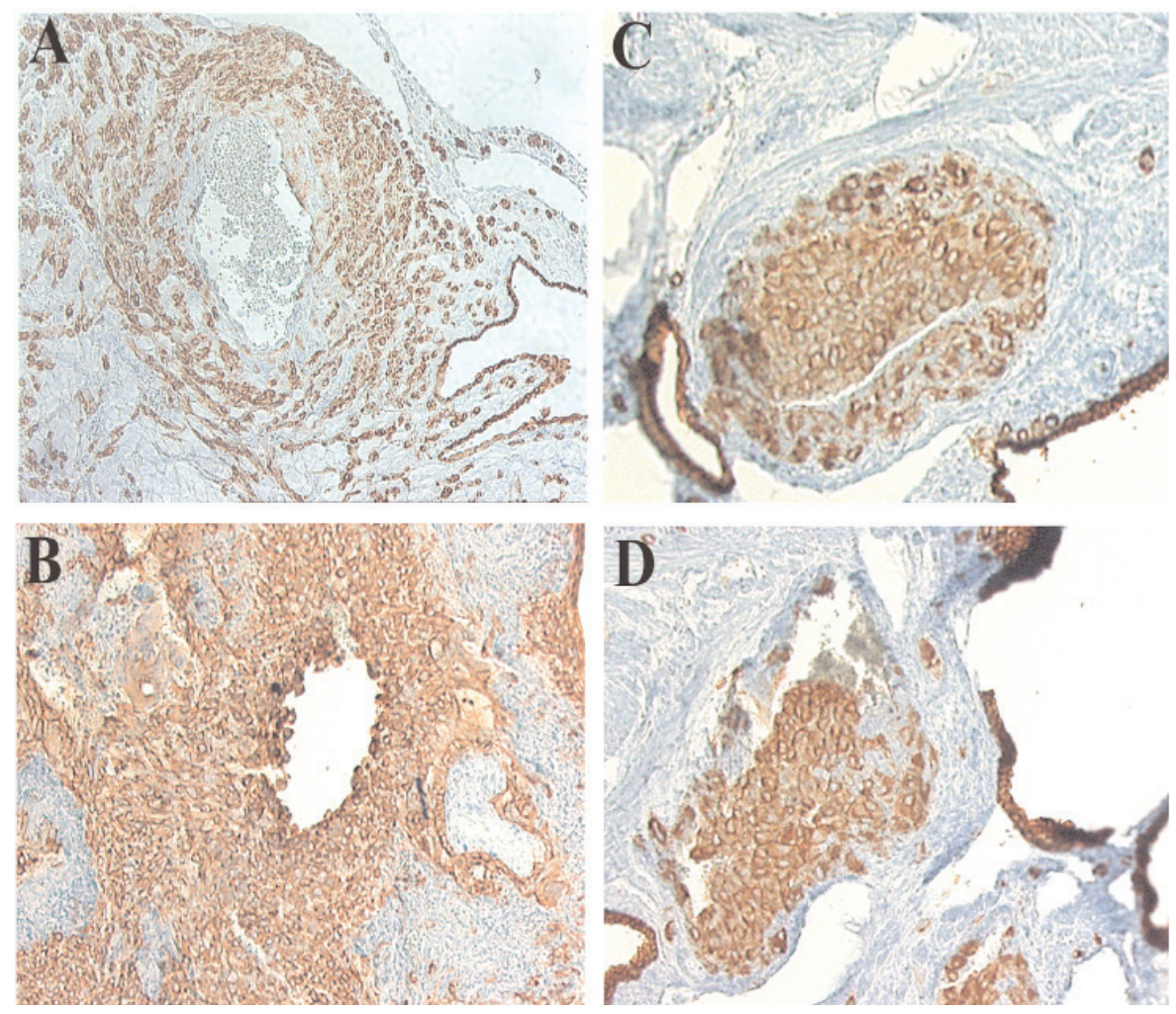

Fig. 2. Immunohistochemistry analysis of trophoblast invasion and arteries remodeling. Sections were stained for cytokeratine 07 to identify trophoblastic cells. A and $\mathbf{B}$ : Periarterial invasion. $\mathbf{C}$ and $\mathbf{D}$ : endovascular invasion.

\section{Human chorionic villi Invasive trophoblast}

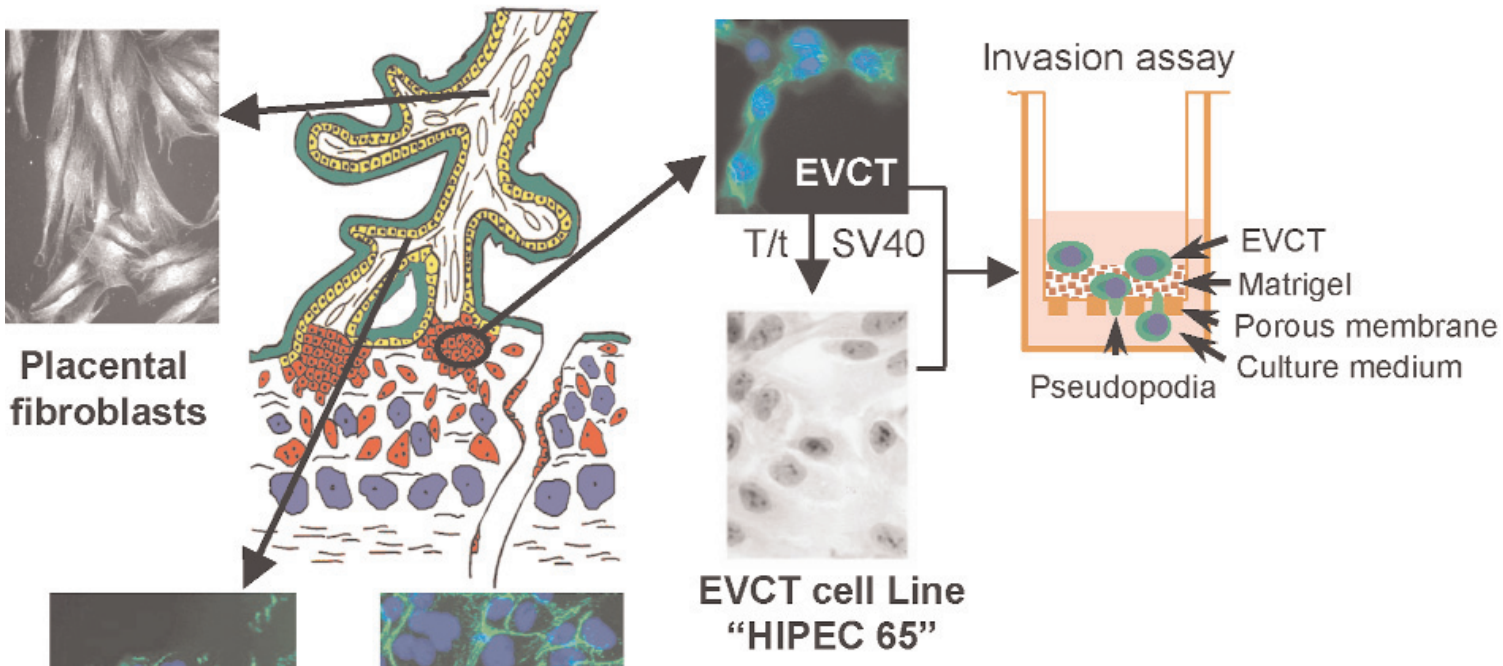

Fig. 3 In vitro models to study human placental cells and trophoblast differentiation. From the same early placenta chorionic villi sequential enzymatic digestions and purification allow to isolate: 1/ extravillous trophoblastic cells which require a matrix to survive and are invasive cells as tested in a Boyden chamber assay, 2/ villous trophoblastic cells which adhere to plastic dishes and fuse to form a syncytiotrophoblast 3 / placental fibroblasts from the mesenchymal core of the villi. Extravillous trophoblastic cells have been immortalized by T/t of SV40 leading to the HIPEC 65 cell line [25].

cy [see for review 10]. It behaves like a super agonist of LH allowing the transformation of cyclic ovary corpus luteum, in gravidic corpus luteum, ensuring the maintenance of ovarian progesterone secretion during the first 6 weeks of pregnancy. HCG is made up of two subunits, an alpha subunit and a beta subunit. The 


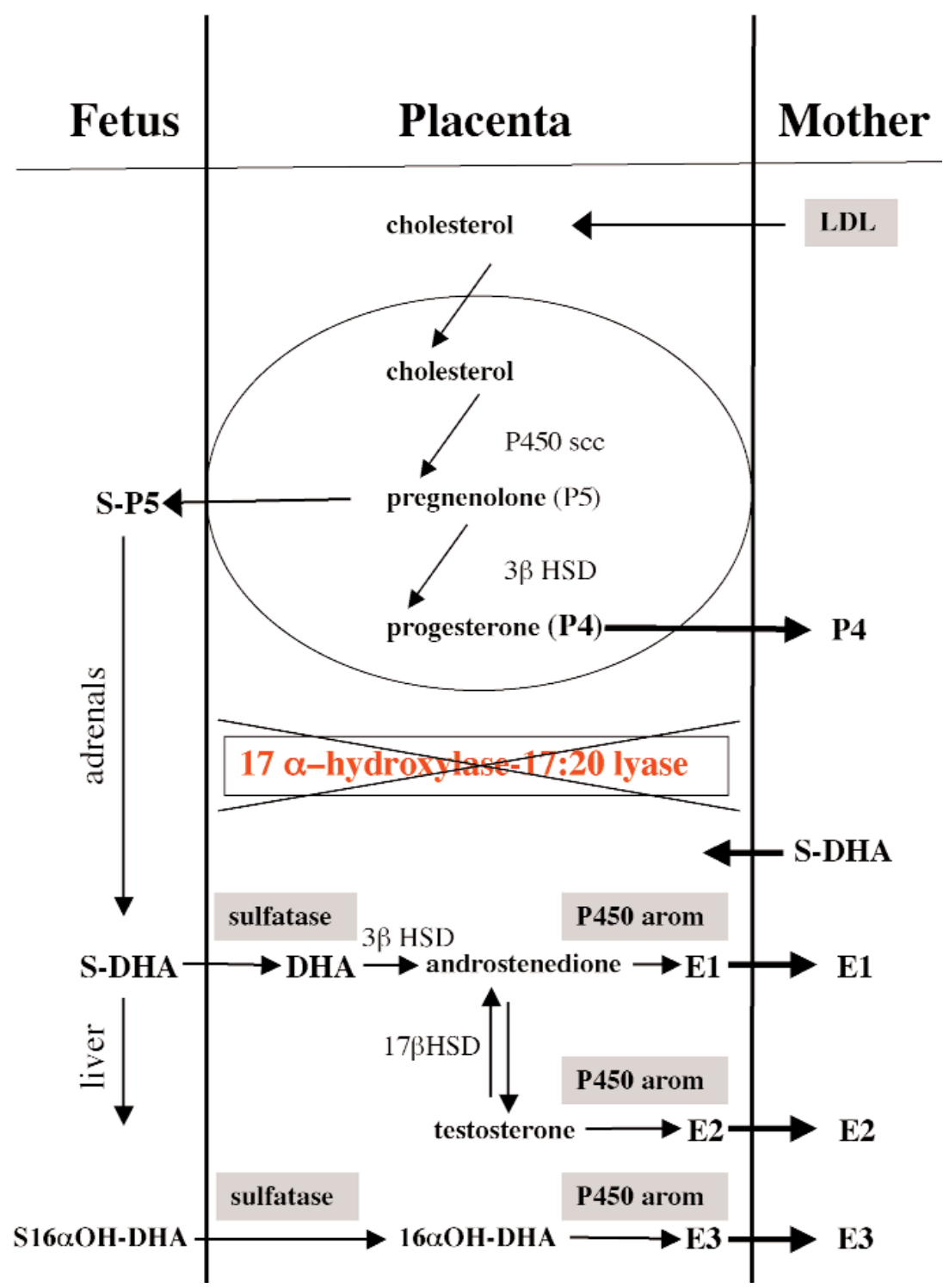

Fig. 4 Scheme of placental steroidogenesis. E1= estrone, E2=estradiol, E3=estriol, P5=pregnenolone, $\mathrm{P} 4=$ progesterone, DHA=dehydroepiandrosterone, MLN64=metastatic lymph node 64 .

alpha subunit is the same in the other glycoproteic hormones (FSH, LH, TSH). The alpha subunit is made up of 92 amino acids with two N-glycosylation sites. It is encoded by only one gene on the chromosome 6q21.123. The beta subunit is made up of 145 amino acids with two sites of N-glycosylation and 4 sites of O-glycosylation. It is encoded by a whole set of genes, six genes beta, a pseudogene CCG beta and a gene LH beta on the chromosome 19q13.3. These genes CG beta evolved by duplication from the gene beta $\mathrm{LH}$ and are controlled differently on the level of their promoter. Compared with LH, the 31 additional amino acids in position C-terminal of hCG, and hCG very high glycosylation level allow its intracellular traffiking towards the apical membrane of the syncytiotrophoblast, its secretion directly in maternal circulation and its prolonged half-life [11]. By an autocrine and paracrine mechanism, hCG plays an essential role in trophoblast differentiation. It stimulates in vitro differ- entiation of the cytotrophoblastic cells into syncytiotrophoblast $[12,13]$. Recently hCG was characterized as a new angiogenic factor involved in the establishment and the development of the human placenta [14]. Several recent studies have demonstrated the importance of the glycosylation state of hCG, which varies with the differentiation stage of the trophoblast as well as the stage of pregnancy [15]. Indeed hCG secreted by the early invasive trophoblast, likely HhCG (hyperglycosylated hCG), but not by the syncytiotrophoblast, promotes trophoblast invasion [16]. In addition, trophoblast cells displaying chromosome 21 trisomy [17] produce abnormal glycosylated forms of hCG with low biological activity. It should be noted that no CG beta genes have been found in mice. It is known for many years that the syncytiotrophoblast secretes in the maternal compartment very large amount of hCS or hPL. This hormone is also found in fetal blood but in much smaller amount than in mater- 
nal blood. The increase in the secretion of hPL during pregnancy follows the evolution of the placental mass, and more particularly the syncytiotrophoblast mass, site of its synthesis. Its real physiological role remains to be elucidated. Indeed normal pregnancies have been described in the absence of hPL secretion. During the last years several studies underline the important role of a growth hormone, specifically produced by the placenta, the placental growth hormone [18]. This hormone, product of GH-V gene, expressed specifically in the syncytiotrophoblast, differs from the pituitary growth hormone by 13 amino acids. It gradually replaces in the maternal circulation, the pituitary growth hormone, which becomes undetectable during the second trimester of pregnancy. Secreted continuously by the placenta, it seems to control the synthesis of maternal IGF-1. Indeed, maternal IGF1 levels are correlated with placental GH levels. This suggests a metabolic role of placental growth hormone, directly involved in the insulino resistance of pregnancy. Placental GH is secreted specifically in the maternal compartment and not detected in fetal circulation. Recently this hormone was shown to be involved in the complex mechanisms which regulate trophobast invasion into the maternal uterine wall. Indeed placental GH secreted by the invasive trophoblast increases trophoblast invasion by an autocrine/paracrine mechanisms [19]. The syncytiotrophoblast also secretes other peptide hormones whose maternal levels increase gradually throughout pregnancy thus reflecting the progressive increase of the syncytiotrophoblastic mass. It is the case of inhibin A and activin A [20] as well as leptin [21] and resistin [22].

The human placenta is the site of an important production of steroid hormones, which are mainly progesterone and estrogens: estriol, estradiol and estrone. At term, the daily placental production of progesterone is about $300 \mathrm{mg}$ [23]. Progesterone acts essentially on the uterus and is required for myometrium quiescence. During the first six weeks of pregnancy, the production of progesterone is primarily carried out by the gravidic ovary corpus luteum. It is thus associated with a secretion of 17 hhydroxy progesterone, produced exclusively by the ovary at this stage of pregnancy. The placental progesterone production gradually takes over with the appearance within the syncytiotrophoblast of the various enzymatic systems necessary for its synthesis. Interestingly some of these enzymes are induced by oxygen. Therefore as soon as 10 weeks of pregnancy when the trophoblastic plugs start to delete, the synthesis of progesterone is high enough to maintain pregnancy in case of ovariectomy. The precursor of progesterone is cholesterol. The de novo synthesis of cholesterol from acetyl CoA is not significant in the placenta. The maternal origin of placental cholesterol has been demonstrated; the trophoblast captures choles- terol carried by maternal plasmatic lipoproteins. Indeed, second and third trimesters of pregnancy are characterized by high levels of maternal circulating total cholesterol, triglycerids, low-density lipoproteins (LDL cholesterol) and high-density lipoproteins (HDL cholesterol). The syncytiotrophoblast apical microvillous membrane, in direct contact with maternal blood presents specific receptors for these lipoproteins (LDL receptor, VLDL receptor, B1 scavenger receptor). It captures and metabolizes LDL by these specific receptor mediated endocytosis. After internalization LDL are degraded in the lysosomes to release cholesterol, which will be used for steroidogenesis, and cellular membranes synthesis. Free cholesterol is then transported by the Sterol Carrier Protein-2 (SCP2) to the external membrane of the mitochondria and then to the internal membrane by the MLN64 (metastatic lymph node 64). MLN64 presents a final domain similar to the stAR(steroidogenic acute regulatory protein), a protein expressed in the other steroidogenic tissues (corpus luteum, adrenals) [24]. In the internal membrane of the mitochondria, P-450 cytochrome scc (cholesterol side chain cleavage), allows the conversion of cholesterol into pregnenolone. This reaction requires electrons provided by the mitochondrial adrenodoxin (ADX) and adrenodoxin reductase (AdRed) activities. Only one gene (P-450XIA) coding for P-450scc and localized on chromosome 15 is present in the placenta, as soon as the 10th week of pregnancy. Pregnenolone is then converted into progesterone by the $3 \beta$ hydroxysteroid-deshydrogenase/isomerase ( $3 \beta$ HSD) localized also in mitochondria. Several genes coding for different $3 \beta$ HSD isoforms are described. In the placenta, only the type 1 gene is expressed. For estrogen synthesis, in contrast to other steroidogenic organ, the placenta does not express the cytochrome P450 17 $\alpha$-hydroxylase-17:20 lyase, and therefore cannot convert pregnenolone and progesterone into androgens. Thus the production of placental estrogens is tributary of a precursor androgen, the sulphate of dehydroepiandrosterone (S-DHA) produced by the maternal and fetal adrenal glands. During pregnancy the estrogen synthesis from fetal adrenal glands origin increases progressively. The S-DHA diffuses from fetal blood to the syncytiotrophoblast and is hydrolized by a sterol steroid sulfatase; DHA is then metabolized in androstendione by a $3 \beta$ HSD. Androstendione is transformed into testosterone by a $17 \beta$ hydroxysteroid dehydrogenase (17 $\beta \mathrm{HSD}$ ) encoded by a gene, HSD17B1, localized on chromosome 17 (17q11q21). C19 androsterone and testosterone are then aromatized in $\mathrm{C} 18$ estrogens (estrone and estradiol respectively) by the P450 cytochrome aromatase, encoded by CYP19 gene, only present in the syncytiotrophoblast. Fetal adrenal S-DHA can also undergo $16 \alpha$-hydroxylation in the fetal liver leading to the for- 
mation of 16 $\alpha$-hydroxy S-DHA, the estriol androgen precursor. Thus $90 \%$ of placental estriol arises from fetal adrenal glands and liver activities. This cooperation between the placenta and the fetus has led to the concept of fetoplacental unit (Fig. 4). If numerous factors such as hCG, cAMP, prostaglandins, have been described to modulate in vitro placental estrogen synthesis, the quality of fetal adrenal glands development remains the essential factor.

If progesterone is absolutely required for the well being of pregnancy, the role of estrogens remains still uncertain. Indeed genetic deficiencies in placental sulfatase or aromatase, leading to very low levels of maternal circulating estrogens are associated with normal pregnancy.

\section{Conclusion}

The human placenta has numerous developmental and endocrine particularities. Therefore investigators must keep in mind the limitation of each experimental models. During the first trimester of pregnancy, which occurs in a low oxygen environment, the invasive trophoblast secretes a large amount of hormones directly involved in the quality of the placentation. After 10-12 weeks of pregnancy, the endocrine trophoblast bathing in maternal blood secretes numerous hormones which take over the maternal metabolism in order to increase the energetic flux to the fetus.

\section{References}

[ 1] Benirschke, K. and Kaufmann, P. Pathology of the human placenta. New-York., Springer-Verlag. 2000.

[ 2] Malassiné A, Frendo JL, Evain-Brion D. Trisomy 21-affected placentas highlight prerequisite factors for human trophoblast fusion and differentiation. Int J Dev Biol. 2009 in press

[ 3] Frendo JL, Olivier D, Cheynet V, Blond JL, Bouton O, Vidaud M, Rabreau M, Evain-Brion D, Mallet F. Direct involvement of HERV-W Env glycoprotein in human trophoblast cell fusion and differentiation. Mol Cell Biol. 2003;23:3566-3574.

[ 4] Pijnenborg R, Robertson W, Brosens I and Dixon G. Trophoblast invasion and the establishment of haemochorial placentation in man and laboratory animals. Placenta. 1981;2:71-91.

[ 5] Burton G, Jauniaux E and Watson A. Maternal arterial connections to the placental intervillous space during the first trimester of human pregnancy: the Boyd collection revisited. Am J Obste. Gynecol. 1999;181:718-724.

[ 6] Hustin J, Jauniaux E and Schapps J. Histological study of the materno-embryonic interface in spontaneous abortion. Placenta. 1987;11:477-480.

[ 7] Tarrade A, Lai Kuen R, Malassiné A, Tricottet V, Blain P, Vidaud $M$ and Evain-Brion D. Characterization of human villous and extravillous trophoblasts isolated from first trimester placenta. Lab Invest. 2001;81:1199-1211.

[ 8] Alsat E, Mirlesse V, Fondacci C, Dodeur M and Evain-Brion D. Parathyroid hormone increases epidermal growth factor receptors in cultured human trophoblastic cells from early and term placenta. J Clin Endol Metab. 1991;73:288-294.
[ 9] Lash GE, Ansari T, Bischof P, Burton GJ et al. IFPA meeting workshop report. Placenta. 2009;supp. 1:4-14.

[10] Jameson J and Hollenberg A. Regulation of chorionic gonadotropin gene expression. Endocr Rev. 1993;14:203221.

[11] Jablonka-Shariff A, Garcia-Campayo V and Boime I. Evolution of lutropin to chorionic gonadotropin generates a specific routing signal for apical release in vivo. $J$ Biol Chem. 2002;277:879-882.

[12] Shi Q, Lei Z, Rao C and Lin J. Novel role of human chorionic gonadotropin in differentiation of human cytotrophoblasts. Endocrinology. 1993;132:1387-1395.

[13] Pidoux G, Gerbaud P, Marpeau O, Guibourdenche J, Ferreira F, Badet J, Evain-Brion D, Frendo JL. Human placental development is impaired by abnormal human chorionic gonadotropin signaling in trisomy 21 pregnancies. Endocrinology. 2007;148:5403-5413.

[14] Zygmunt M, McKinnon T, Herr F, Lala PK, Han VK. Characterization of human chorionic gonadotropin as a novel angiogenic factor. Mol Hum Reprod. 2005;11:261-267.

[15] Diaz-Cueto L, Barrios-de-Tomasi J, Timossi C, Mendez JP, Ulloa-Aguirre A. More in-vitro bioactive, shorter-lived human chorionic gonadotropin charge isoforms increase at the end of the first and during the third trimesters of gestation. Mol Hum Reprod. 1996;2:643-650.

[16] Handschuh K, Guibourdenche J, Tsatsaris V, Guesnon M, Laurendeau I, Evain-Brion D, Fournier T. Human chorionic gonadotropin produced by the invasive trophoblast but not the villous trophoblast promotes cell invasion and is down-regulated by peroxisome proliferator-activated receptor-gamma. Endocrinology. 2007;148:5011-5019.

[17] Frendo J-L, Guibourdenche J, Pidoux G, Vidaud M, Luton D, Giovangrandi Y, Porquet D, Muller F and Evain-Brion D. Trophoblast production of a weakly bioactive human chorionic gonadotropin in trisomy 21 -affected pregnancy. $J$ Clin Endocinol Metab. 2004;89:727-732.

[18] Lacroix M-C, Guibourdenche J, Frendo J-L, Muller F and Evain-Brion D. Human placental growth hormone: an overview of recent data. Placenta. 2002;Suppl A:S87-94.

[19] Lacroix M-C, Guibourdenche J, Fournier T, Laurendeau I, Igout A, Goffin V, Pantel J, Tsatsaris V and Evain-Brion D. Stimulation of human trophoblast invasion by placental growth hormone. Endocrinology. 2005;146:2434-2444.

[20] Debieve, F., Pampfer, S. and Thomas, K. Inhibin and activin production and subunit expression in human placental cells cultured in vitro. Mol Hum Reprod. 2000; 6: 743-749.

[21] Sagawa N, Yura S, Itoh H, Mise H, Kakui K, Korita D, Takemura M, Nuamah MA, Ogawa Y, Masuzaki H, Nakao K and Fujii S. Role of leptin in pregnancy-a review. Placenta. 2002;Suppl A:S80-86.

[22] Yura S, Sagawa N, Itoh H, Kakui K, Nuamah MA, Korita D, Takemura M, Fujii S.Resistin is expressed in the human placenta. J Clin Endocrinol Metab. 2003;88:1394-1397.

[23] Payne, AH and Hales DB. Overview of steroidogenic enzymes in the pathway from cholesterol to active steroid hormones. Endocrine Review. 2004; 25: 947-970.

[24] Tuckey RC, Bose HS, Czerwionka I, Miller WL. Molten globule structure and steroidogenic activity of N-218 MLN64 in human placental mitochondria. Endocrinology. 2004; 145:1700-1707

[25] Pavan L, Tarrade A, Hermouet A, Delouis C, Titeux M, Vidaud M, Thérond P, Evain-Brion D, Fournier T. Human invasive trophoblasts transformed with simian virus 40 provide a new tool to study the role of PPARgamma in cell invasion process. Carcinogenesis. 2003;24:1325-1336. 